\title{
UNA COMUNIDAD PARA EL CONOCIMIENTO: Naturaleza del saber filosófico*
}

\section{Rafael Carrillo}

Quiero dar las gracias a los que me han invitado a asistir a la inauguración de este grupo de trabajo, especialmente al profesor Silvio Avendaño, alumno mío. Agradezco, además, las generosas palabras sobre mí, con las cuales Numas Armando Gil acaba de abrir el seminario acerca de Hegel. Se me ha invitado a inaugurar un seminario sobre Hegel y no a hablar sobre él, lo que hubiera hecho con mucho gusto si se me hubiera dado el tiempo para preparar una ponencia sobre este filósofo. Lo digo porque me lo acaban de informar algunos de sus compañeros: "vamos a ver qué nos dice usted sobre Hegel". No se me ha invitado a hablar de Hegel. En todo caso, de lo que se trata es de inaugurar una comunidad de trabajo en general, y de trabajo filosófico, naturalmente, pues se trata de profesores de filosofía, entre ellos, muchos alumnos míos de la Universidad Nacional.

Este grupo de trabajo lo llamo yo una comunidad de trabajo, traduciendo literalmente la expresión que se usa entre los estudiantes alemanes para fundar una sociedad con las mismas finalidades con que se funda la suya: una Arbeitsgemeinschaft (Gemeinschaft, comunidad; Arbeit, trabajo). Una Arbeitsgemeirischaft llaman los alemanes a esto mismo que ustedes quieren inaugurar hoy. Se trata, pues, de decir unas palabras previas muy sencillas, para saludar la inauguración de esa Arbeitsgemeinschaft que ustedes han fundado. Y como no voy a hablar de Hegel, lo más indicado es decir algunas palabras que, así lo deseo, ustedes deben tener siempre presentes durante el desarrollo del trabajo en esta comunidad. Dichas palabras tienen qué decir lo que tanto he repetido en mis clases, lo que tanto he reiterado en conversaciones, unas palabras acerca del carácter mismo de la filosofía. En síntesis. ¿De qué se trata cuando estamos hablando de filosofía? Lo mejor es tomar como punto de partida lo que filosofía significó ya en los comienzos mismos en la cual aparece. La filosofía surge - sin meternos ahora en el problema de silos orientales tuvieron o no filosofía (eso es discutible, hay unos que lo aceptan y otros que lo niegan) — la filosofía aparece en Grecia. La filosofía es, como dice Heidegger, griechisches Geschäft, un asunto griego, un comercio griego literalmente traducido. Es cuestión de Grecia, y para él, solamente de Grecia. Entonces, la filosofía aparece en Grecia, y aparece como ustedes saben muy bien, primero en Jonia, específicamente en Mileto. Pero lo importante es que esa palabra filosofía nace después de que surge la palabra filósofo en Grecia. Y la palabra filósofo emerge después de un tiempo de investigación filosófica, en Heráclito mismo como investigador de la naturaleza, y específicamente como investigador de la naturaleza de las cosas. Tenemos, entonces, primero, que aquí en Grecia, en la época en la cual se forma la palabra, en Heráclito concretamente, el término filósofo aparece como un ser que investiga. $Y$ no se dice nada más. Después se formará la palabra filosofía que significa investigación de la naturaleza. Este significado de investigación de la naturaleza pasará posteriormente a conformar la idea de amor a la sabiduría, en el sentido de filosofía.

\footnotetext{
* Palabras de Rafael Carrillo (1907-96) pronunciadas el 13 de marzo de 1987 en la inauguración del Seminario "Hegel y la pedagogía", promovido por la Universidad Pedagógica Nacional. Su contenido proviene de una grabación hecha por los estudiantes de la UPN en aquella ocasión. Con la difusión de este documento, la Revista Colombiana de Educación se une al recuerdo del profesor Carrillo, recientemente fallecido en la ciudad de Valledupar G.C.
} 
Si nosotros perseguimos en la historia del desarrollo del pensamiento filosófico el sentido de las palabras filosofía y filósofo, encontramos que ya, desde Heráclito, estas palabras aparecen designando a un ser que investiga. $Y$ ese investigar es lo mismo que un saber, lo mismo que un conocer, es decir, la palabra filosofía aparece indicando conocimiento, investigación, saber, y no se nos dice nada más. Se nos dice que es un conocer, que es un saber, que es un investigar, pero nunca se nos dice que es un conocer para algo. En todas las grandes definiciones de filosofía, a través de la historia, la palabra filosofía significa sencillamente un saber por el saber, un conocer por conocer, un investigar por investigar. Esa es la naturaleza de la filosofía. Así se considera en Grecia la naturaleza, de la filosofía misma. Y esa definición de un saber por el saber —o mejor esa preocupación - la encontramos no solamente en la época en que aparece la filosofía sino mucho antes. El griego era, por naturaleza un hombre que quería conocer, y en el siglo IX antes de Cristo, cuando aparece Homero, esa significación del saber por el saber sigue estando presente en el espíritu griego. Hay una leyenda sobre Homero en relación con esta concepción del saber del hombre griego.

Esta leyenda nos dice que Homero murió de congoja por no poder descifrar lo que unos marinos le propusieron (tomo el dato directamente de Ortega y Gasset).

Pues bien, este saber por el saber lo encontramos a través de toda la historia del pensamiento filosófico. Si llegamos, por ejemplo, a la filosofía de Platón —para dar un salto desde Heráclito- encontramos esta concepción del saber por el saber. Saber es el vocablo, hablando llanamente, de donde proviene sabiduría. Y sabiduría en Grecia, en Aristóteles específicamente, es filosofía. En Platón encontramos esa concepción de la filosofía como un saber por el saber. Es lo que él llama la episteme. La episteme es la ciencia del ser, del ser supremo. Exactamente lo mismo que en Heidegger, es un saber por el saber, ese conocer el sen Una concepción de la filosofía o de la sabiduría que es en el fondo la misma que encontramos en Heráclito. La naturaleza de las cosas, que es el objeto de la filosofía o el conocimiento que tiene por objeto la filosofía, es un conocimiento por conocer. Querer conocer la naturaleza de las cosas, no para hacer algo con ella, porque naturaleza es en griegophisys, exactamente lo mismo que esencia. $Y$ no conocemos la esencia de una cosa para hacer algo con ella porque no hay nada que esté más allá de ese conocimiento. La esencia no se presta a ser útil sino que es un conocimiento por conocer, un conocimiento fundamental. Pero del conocimiento de la esencia no se puede deducir un conocimiento de algo para algo. El para está prohibido en la época de toda la filosofía griega. No hay una finalidad utilitaria. Y la filosofía seguirá teniendo a través de todas las épocas la significación que tuvo en Grecia: que es una ciencia y que es una ciencia inútil. Si afirmo esto, entonces ¿para qué la filosofía?

Esta es una pregunta sin sentido cuando uno se refiere a la filosofía. La filosofía es una ciencia inútil, pero de esa ciencia inútil se ha derivado toda la cultura occidental y toda la técnica que hoy nos invade y todos los conocimientos que hoy tenemos de las cosas y de la naturaleza. No habría podido suceder eso si no se hubiera empezado con la filosofía, que es una ciencia completamente inútil. Ahora bien, en Platón encontramos la episteme como una ciencia del ser, y no más. Pero aun suponiendo que en Platón ese conocimiento del ser, esa ciencia del ser último, esa episteme fuera una episteme cuyo último grado fuera la educación del filósofo, y que el filósofo se educaba para gobernar y para realizar la idea del bien, sigue teniendo la idea del bien el mismo carácter de un objeto completamente inútil. No se olvide que el mismo Platón reconocía el carácter utópico de su República, de su politeia. 
Si pasamos a Aristóteles encontramos exactamente lo mismo. Paso de largo por las diferentes definiciones de la filosofía en donde ésta se considera como una ciencia que consiste en el saber por el saber mismo, y llego a un pasaje de la Metafísica de Aristóteles que me interesa leer porque es algo sumamente provechoso para que se tenga en cuenta en esta comunidad filosófica que se ha fundado aquí en la Universidad Pedagógica Nacional. Dice Aristóteles:

Que no se trata de una ciencia productiva es evidente ya por los primeros que filosofaron. Pues los hombres comienzan, y comenzaron siempre en su filosofar movidos por la admiración; al principio, admirados ante los fenómenos sorprendentes más comunes; luego, avanzando poco a poco y planteándose problemas mayores, con los cambios de la luna y los relativos al sol y a las estrellas, y la generación del universo. Pero el que plantea un problema o se admira, reconoce su ignorancia... De suerte que si filosofaron para huir de la ignorancia, es claro que buscaban el saber en vista del conocimiento, y no por alguna utilidad. Y así lo atestigua lo ocurrido. Pues esa disciplina comenzó a buscarse cuando ya existían todas las cosas necesarias y las relativas al descanso y al ornato de la vida. Es, pues, evidente que no la buscamos por ninguna otra utilidad, sino que, así como llamamos hombre libre al que es para sí mismo y no para otro, así consideramos a la filosofía [o la sabiduría] como la única ciencia libre, pues ésta sola es para sí misma. Por eso también su posición podría, en justicia, ser considerada impropia del hombre, pues la naturaleza humana es esclava en muchos aspectos. De suerte que, según Simónides, "sólo un dios puede tener este principio" [de poseer la sabiduría], aunque es indigno de un varón no buscar la ciencia a él proporcionada (Metafísica, libro 1, 2).

Queda, pues, dicho cuál es la naturaleza de la ciencia, qué busca la filosofía y cuál es la meta que debe alcanzar la indagación filosófica. Tomemos ahora otra definición de la filosofía que está en relación con uno de los puntos que ustedes tienen aquí como propósito de investigación. Tomemos la definición que da Hegel de filosofía. ¿Acaso dice Hegel —o podría habérsele ocurrido alguna vez- que la filosofía es una ciencia que sirve para esto y para aquello otro? ¿Que es una ciencia instrumento? No, de ninguna manera. En ningún momento se le había ocurrido una definición de la filosofía como un medio; sólo como una meta. Por eso la define diciendo que es el conocimiento de lo absoluto. Como ustedes saben, esta palabra, lo absoluto, define no solamente lo que es la filosofía de Hegel en sus diferentes fases, sino que es el tema mismo del idealismo alemán. Schelling, Fichte, Hegel, y algunos coetáneos como Goethe, persiguen también lo absoluto. La búsqueda de lo absoluto es la meta misma de la filosofía. La ciencia, Hegel habla siempre de la ciencia, de la ciencia sin más. No habla de filosofía ni de ciencia filosófica. Es autor de obras tituladas Ciencia de la lógica, Enciclopedia de las ciencias filosóficas, etc. Y lo mismo Fiehte quien desarrolló una teoría de la ciencia en varias versiones.

Pues bien, una de las cosas que más me interesaron en Heidelberg -cuando escuchaba la cuarta o quinta conferencia del profesor Gadamer- es esto que quiero que se graben en sus mentes: cuando en los tiempos del idealismo alemán se hablaba de ciencia, hay que entender no la ciencia natural ni la ciencia de un objeto determinado, sino simple y llanamente la filosofía. Y así aparece en Hegel cuando habla de ciencia. La filosofía es la ciencia de lo absoluto, dice Hegel —y lo mismo pasa con Fichte y Schelling. Se habla de filosofía, pero no se habla de una filosofía para algo sino de un saber como saber, de un conocimiento como conocimiento. En el mismo Kant encontramos también esa concepción. Para Kant la filosofía es - después de la rectificación de Heidegger relativa a la Crítica de la razón pura, obra que se venía entendiendo como una teoría del conocimiento- ciencia del ser, exactamente lo mismo que en Platón y en Parménides, y nunca ciencia de algo particular. A veces Kant emplea la palabra metafísica en el sentido de una crítica de la razón pura. Pero tampoco en este sentido encontraríamos una 
concepción de la filosofía como medio. Entonces, para dejar expresado un deseo en la inauguración de esta comunidad de trabajo, quisiera que esta comunidad sea lo mismo que ustedes se han propuesto al fundarla: una investigación. Este es el único medio para llegar a realizar un progreso en el conocimiento y alcanzar un desempeño serio en los campos de la filosofía. Ustedes no han pensado nunca aquí, al fundar esta comunidad, para qué van a investigar. No se han propuesto esta pregunta. No se debe proponer y no existe una respuesta a esta pregunta. Se va a investigar por investigar y ese es el sentido mismo de la comunidad filosófica que ustedes han fundado. Por eso quiero leer, para terminar, unas palabras del discurso inaugural de Hegel cuando inició el curso sobre Historia de la Filosofía en el año de 1816 en la universidad de Heidelberg:

Lo único que ahora tengo derecho a pediros, es que por encima de todo, sólo depositéis vuestra confianza en la ciencia. En la ciencia y en vosotros mismos. El valor de la verdad, de la fe en el poder del espíritu es la condición de la filosofía y ese valor de la verdad es sencillamente el mismo saber por el saber [el subrayado es mío].

Si la filosofía es desinterés, si la filosofía es la búsqueda de un saber por el saber, entonces ustedes han fundado una comunidad para el saber, para el conocimiento, para la investigación; no digamos de qué por el momento. En mi concepto, esta comunidad de trabajo que ustedes han creado en la Universidad Pedagógica Nacional se confunde con la definición misma de filosofía. Por eso, si se me preguntara, si se me exigiera una definición ostensiva de filosofía, yo diría en este momento: la filosofía es esta comunidad de trabajo. Muchas gracias. [Aplausos]. 